\title{
Patrick Labarthe, Baudelaire et la tradition de l'allégorie
}

\section{Mario Richter}

\section{Q OpenEdition}

1 Journals

\section{Edizione digitale}

URL: http://journals.openedition.org/studifrancesi/4431

DOI: 10.4000/studifrancesi.4431

ISSN: 2421-5856

\section{Editore}

Rosenberg \& Sellier

\section{Edizione cartacea}

Data di pubblicazione: 1 settembre 2016

Paginazione: 354

ISSN: 0039-2944

\section{Notizia bibliografica digitale}

Mario Richter, « Patrick Labarthe, Baudelaire et la tradition de l'allégorie », Studi Francesi [Online], 179 (LX | II) | 2016, online dal 01 septembre 2016, consultato il 18 septembre 2020. URL : http:// journals.openedition.org/studifrancesi/4431; DOI : https://doi.org/10.4000/studifrancesi.4431

Questo documento è stato generato automaticamente il 18 settembre 2020.

\section{(c) (i) $\odot$}

Studi Francesi è distribuita con Licenza Creative Commons Attribuzione - Non commerciale - Non opere derivate 4.0 Internazionale. 


\title{
Patrick Labarthe, Baudelaire et la tradition de l'allégorie
}

\author{
Mario Richter
}

\section{NOTIZIA}

PATRICK LABARTHE, Baudelaire et la tradition de l'allégorie, Préface d'Yves Bonnefoy, Genève, Droz, 2015, 919 pp.

1 Di quest'opera, pubblicata da Droz allo scadere del secolo scorso (1999), si è già reso conto nel n. 132 (settembre-dicembre 2000, pp. 629). Da qualche tempo esaurita, è ora opportunamente riproposta nella sua forma originale, pur lievemente riveduta e corretta in qualche marginale dettaglio, dallo stesso editore in una sua collana di più larga diffusione e accessibilità («Titre courant», n. 56) meritando anche l'aggiunta di un'ampia e nutritiva «Préface» di Yves Bennefoy, un «frontispice» che ne costituisce la novità sotto il trasparente titolo Leurre et vérités des allégories. L'acclamato poeta $\mathrm{e}$ saggista, al cui pensiero e alla cui opera nella prima edizione del libro Labarthe riconosceva il suo debito, dedica ora al tema dell'allegoria una sua impegnata riflessione poetico-critica, dalla quale è anche possibile desumere una parte significativa della sua attuale visione estetica. Rivolgendosi con parole confidenziali al «cher Patrick» e passando in termini prevalentemente allusivi soprattutto attraverso una rilettura di Le Cygne, Bonnefoy illustra la sua convinzione che l'autentica poesia, pur avendo una propensione per il «rêve métaphysique», giunga ad avere uno stretto rapporto, «au fond de ce rêve», con il reale, e sostiene che «l'allégorie est impénétrable à la pensée qui ne se veut que conceptuelle» per arrivare ad affermare, tramite una ricca serie di pertinenti esempi baudelairiani, che essa «est de l'aspiration poétique un lieu de manifestation des plus naturels dans la parole, et même de son élan la forme comme cristallisée». Riconoscendo a sua volta il proprio debito al presente libro, con amichevole umiltà il poeta così conclude il suo «frontispice»: «Je suis revenu à Baudelaire, mais ce ne sera pas, cher Patrick, pour priver plus longtemps nos lecteurs de l'attention que vous lui portez. Je n'ai que trop différé la lecture d'un livre sans 
lequel les réflexions que je viens de faire n'auraient guère pu avoir lieu. J'ai cheminé près de vous, bénéficiant de votre pensée. Que mon frontispice à votre livre ne soit plus maintenant que la page que le lecteur doit tourner!». 